\title{
Novel Spectrophotometric Methods for the Determination of Selegiline Hydrochloride in Bulk and Its Pharmaceutical Preparation
}

\author{
Kumble Divya and Badiadka Narayana \\ Department of Post-Graduate Studies and Research in Chemistry, Mangalore University, Mangalagangothri 574199, India \\ Correspondence should be addressed to Badiadka Narayana; nbadiadka@yahoo.co.uk
}

Received 27 November 2013; Accepted 18 January 2014; Published 23 February 2014

Academic Editors: Y. C. Ling and T. Strunskus

Copyright (C) 2014 K. Divya and B. Narayana. This is an open access article distributed under the Creative Commons Attribution License, which permits unrestricted use, distribution, and reproduction in any medium, provided the original work is properly cited.

A simple and highly selective spectrophotometric method has been developed for the determination of selegiline hydrochloride in bulk and formulations. Method A is based on the oxidation of 3-methyl-2-benzothiazolinone hydrazone in the presence of ceric ammonium sulphate, followed by its coupling reaction with drug to form a colored product having $\lambda_{\max }$ of $629 \mathrm{~nm}$. Method B is based on the coupling reaction of drug with 4 -aminoantipyrine to give a new ligand that reacts with copper(II) to give intense bluish red colored chelate which is measured at $539 \mathrm{~nm}$. Beer's law is obeyed in the range of $10.00-85.00 \mu \mathrm{g} \mathrm{mL}^{-1}$ with molar absorptivity of $0.98 \times 10^{4}$ for method A and $20.00-120.00 \mu \mathrm{g} \mathrm{mL}^{-1}$ with molar absorptivity of $0.94 \times 10^{4}$ for method B. The optimum reaction condition and the analytical parameters are evaluated. The results obtained indicate that the methods are free from interference of the ingredients; thus they are successfully applied to pharmaceutical formulations.

\section{Introduction}

Selegiline hydrochloride (SGE) (Figure 1) (deprenyl), [(R)(2)- $N$-methyl-(1-phenyl-2-propyl)- $N$-propinylamine] hydrochloride [1], is a levomethamphetamine derivative which belongs to a class of drugs called phenethylamines [2]. SEG is a selective, irreversible inhibitor of monoamine oxidase (MAO-A) [3]. It is used for the treatment of earlystage Parkinson's disease, depression, and senile dementia [4]. It is useful adjunct in the treatment of cocaine addiction [5]. SEG (brand name Anipryl) is also used (at extremely high dosages relative to humans) in veterinary medicine to treat the symptoms of Cushing's disease and cognitive dysfunction (canine cognitive dysfunction) in dogs [6]. Recommended dosage of SEG is about $10 \mathrm{mg} /$ day; further increase in the dosage will lead to the nonselective inhibition of MAO [7]. Therefore, it is essential to develop a standard analytical method for monitoring residual drug in bulk and in pharmaceutical formulations. The pharmaceutical importance of drug has prompted us to devise methods for the rapid determination of SEG. A very few methods are reported in the literature for the determination of SEG in pharmaceutical formulations which include high performance liquid chromatography [8-12], gas chromatography $[13,14]$, fluorescence polarization immunoassay (FPIA) and gas chromatography-mass spectrometry (GC/MS) [15], spectrofluorometry [16], and stereoselective analyses [17]. The literature survey reveals that so far there is no visible spectrophotometric method for the analysis of SEG.

Unlike gas chromatograph and high performance liquid chromatograph the UV-Visible spectrophotometer is a simple, low-cost instrument and on the other hand, in terms of simplicity and expense, the method could be considered superior in comparison with the previously reported methods. Thus, the present work reports new spectrophotometric methods for the determination of SEG in pure and in pharmaceutical formulations.

\section{Materials and Methods}

2.1. Apparatus. A UV-Visible spectrophotometer (SHIMADZU, UV 2550, Japan) with $1 \mathrm{~cm}$ quartz cells was used for the absorbance measurements. 
<smiles>C#CCN(C)[C@H](C)Cc1ccccc1</smiles>

FIGURE 1: Chemical structure of SEG.

2.2. Chemicals and Reagents. All the reagents were of analytical grade and used without further purification. All the solutions were prepared in distilled water. SEG bulk drug was obtained as gift sample from CAD Pharma Inc., Bangalore, India. Pharmaceutical formulations of SEG were obtained commercially.

2.3. Standard Drug Solution. Stock solution of SEG $(1000 \mu \mathrm{g} / \mathrm{mL})$ was prepared by dissolving $100 \mathrm{mg}$ of SEG in distilled water and making the volume $100 \mathrm{~mL}$ in a standard volumetric flask. The stock solution was diluted approximately to get working concentration.

3-Methyl-2-benzothiazolinone Hydrazone (MBTH, 0.2\% w/v). $0.2 \mathrm{~g}$ of MBTH was accurately weighed and dissolved in $100 \mathrm{~mL}$ of distilled water.

Ceric Ammonium Sulphate (CAS, 1\% w/v). $1 \mathrm{~g}$ gm of CAS was dissolved in $20 \mathrm{~mL}$ of $0.1 \mathrm{~N}$ sulphuric acid and the volume became $100 \mathrm{~mL}$.

4-Aminoantipyrine (AAP, $0.1 \% w / v)$. $0.1 \mathrm{~g}$ of AAP was dissolved in $10 \mathrm{~mL}$ of ethanol and made up to be $100 \mathrm{~mL}$ with distilled water.

Copper(II) Chloride (1\%w/v). $1 \mathrm{~g}$ of $\mathrm{Cu}(\mathrm{II})$ chloride was accurately weighed and dissolved in $100 \mathrm{~mL}$ of distilled water.

\subsection{Recommended Procedures}

Method A. Aliquots containing 10.00-100.00 $\mu \mathrm{g} \mathrm{mL}^{-1}$ of SEG were transferred into a series of $10 \mathrm{~mL}$ volumetric flasks. Then $1.0 \mathrm{~mL}$ of $0.2 \% \mathrm{MBTH}$ and $1.0 \mathrm{~mL}$ of $1 \%$ CAS solutions were added and the flasks were kept aside for $15 \mathrm{~min}$ at room temperature. The solutions in each flask were made up to the mark with distilled water and the absorbance was measured at $629 \mathrm{~nm}$ against reagent blank.

Method B. Aliquots containing 20.00-120.00 $\mu \mathrm{g} \mathrm{mL}^{-1}$ of SEG were transferred into a series of $10 \mathrm{~mL}$ volumetric flasks, followed by the addition of $2 \mathrm{~mL}$ of $1 \%$ AAP and $1 \mathrm{~mL}$ of $0.1 \%$ Copper chloride.The resulting reddish violet colored mixtures were kept aside for $10 \mathrm{~min}$ and make up the solution to be $10 \mathrm{~mL}$ with acetone; the absorbance values were measured at $539 \mathrm{~nm}$ against the reagent blank solution.

2.5. Preparation of Pharmaceutical Formulation. Twenty tablets of SEG (5 mg) were crushed thoroughly in a mortar,

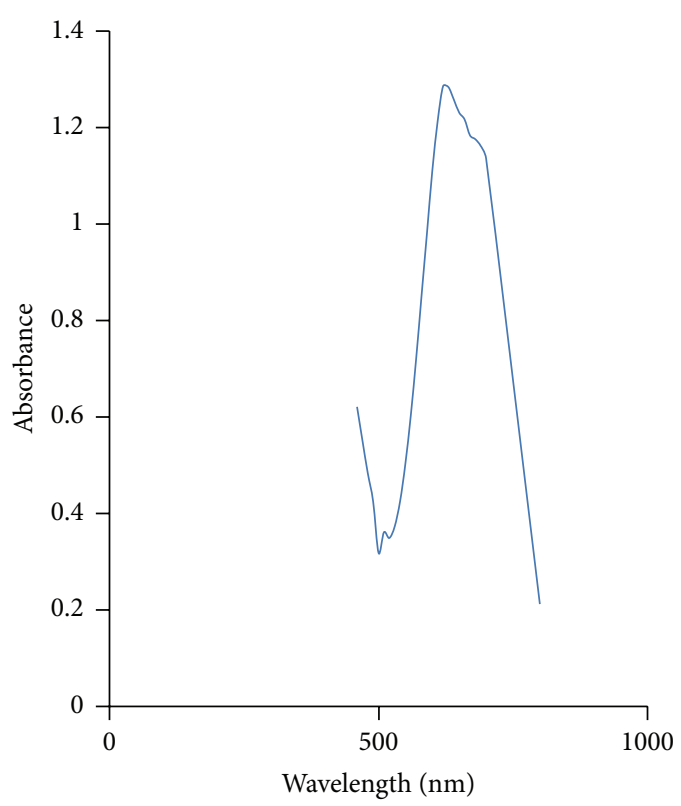

Figure 2: Absorption maximum for method A.

dissolved in $30 \mathrm{~mL}$ of ethanol, and diluted to $100 \mathrm{~mL}$ by using water. The solution was filtered through Whatman filter paper number 41 and diluted quantitatively with water to obtain a suitable concentration for the analysis. A convenient aliquot was then subjected to the analysis by using proposed method.

\section{Results and Discussion}

Method A. In this method MBTH undergoes oxidation with $\mathrm{Ce}(\mathrm{IV})$, by losing two electrons and one proton to form electrophilic intermediate, which act as the active coupling species $[18,19]$. This intermediate undergoes electrophilic substitution reaction with SEG (Scheme 1) to give bluish green colored product that can be measured at $629 \mathrm{~nm}$ (Figure 2).

Method B. In this method AAP reacts with SEG to form a new ligand (Scheme 2) having low sensitivity at $329 \mathrm{~nm}$. This sensitivity has been increased by complexation with $\mathrm{Cu}$ (II) [20] to give intense bluish red colored chelate which can be measured at $539 \mathrm{~nm}$ (Figure 3).

3.1. Determination of Effective Reagents Concentration. Experiments were carried out to optimize the reaction condition for complete color formation. It was found that $1.0 \mathrm{~mL}$ of $0.2 \% \mathrm{MBTH}$ and $1.0 \mathrm{~mL}$ of $1 \% \mathrm{Ce}(\mathrm{IV})$ solutions for method $\mathrm{A}$ and $2 \mathrm{~mL}$ of $1 \% 4$-AAP and $1 \mathrm{~mL}$ of $0.1 \% \mathrm{Cu}(\mathrm{II})$ solutions for method II were found to be optimum to get the stable and maximum color intensity.

3.2. Quantification. In order to analyze the linearity of the developed methods, absorbance was measured for a series of solutions containing increasing amounts of SEG under optimum condition. Regression analysis of Beer's law plots (Figures 4 and 5) at their respective values revealed good corre- 


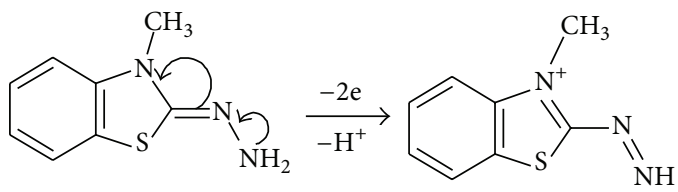

(I)

(II)

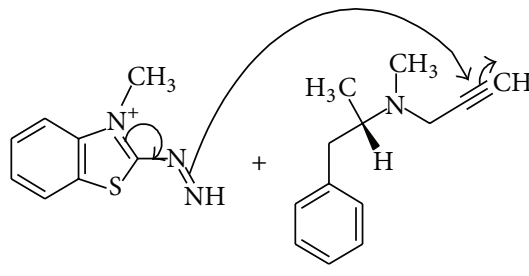

SEG<smiles>C=C(CN(C)C(C)Cc1ccccc1)N/N=c1\sc2ccccc2n1C</smiles>

Colored product

Scheme 1: Probable reaction of SEG with MBTH.

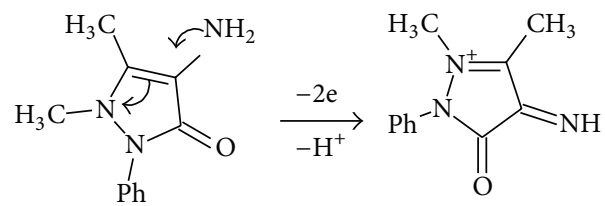<smiles>C=C(CN(C)[C@H](C)Cc1ccccc1)Nc1c(C)n(C)n(-c2ccccc2)c1=O</smiles>

SEG<smiles>C=C(CN(C)[C@H](C)Cc1ccccc1)Nc1c(C)n(C)n(-c2ccccc2)c1=O</smiles>

Scheme 2: Probable reaction of SEG with AAP and $\mathrm{Cu}$ (II) chloride.

lation. The validity of Beer's law, molar absorptivity, and Sandell's sensitivity values were evaluated and were given in Table 1 . The proposed methods showed excellent linearity for the determination of SEG drugs with a good correlation coefficient. Limit of detection (LOD) and limit of quantification (LOQ) were calculated as per the ICH guidelines [21].

3.3. Accuracy and Precision. Accuracy and precision of the proposed methods were tested by carrying out determinations of five replicates of bulk and commercial samples for both the methods, whose concentrations lie within Beer's law range. The relative standard deviation (RSD) and relative error results indicated that the methods were precise and accurate. The relative error (\%) which is a measure of accuracy and RSD (\%) which is a measure of precision were summarized in Table 2, revealing the high accuracy and precision of the methods.

3.4. Stoichiometry of the Reaction Product. The stoichiometric ratio of the colored product of method $\mathrm{A}$ and method $\mathrm{B}$ 
TABLE 1: Spectral and statistical data for the determination of SEG.

\begin{tabular}{lcc}
\hline Parameters & Method A & Method B \\
\hline$\lambda_{\max }(\mathrm{nm})$ & 629 & 539 \\
Beer's law limits $(\mu \mathrm{g} / \mathrm{mL})$ & $10.00-85.00$ & $20.00-120.00$ \\
Molar absorptivity $\left(\mathrm{L} \mathrm{mol}^{-1} \mathrm{~cm}^{-1}\right)$ & $0.98 \times 10^{4}$ & $0.94 \times 10^{4}$ \\
Sandell's sensitivity $\left(\mu \mathrm{g} \mathrm{cm}^{-2}\right)$ & $3.33 \times 10^{-2}$ & $1.98 \times 10^{-2}$ \\
Limit of detection* $\left(\mu \mathrm{g} \mathrm{mL}^{-1}\right)$ & 0.8059 & 0.4347 \\
Limit of quantification* $\left(\mu \mathrm{g} \mathrm{mL}^{-1}\right)$ & 2.4423 & 1.3173 \\
Regression equation** & $Y=a+b X$ & $Y=a+b X$ \\
Slope $(b)$ & 0.0124 & 0.0046 \\
Intercept $(a)$ & 0.1428 & 0.0047 \\
Correlation coefficient $(r)$ & 0.9924 & 0.9987 \\
\hline
\end{tabular}

${ }^{*}$ Limit of detection calculated according to ICH guidelines.

${ }^{* *} Y$ is the absorbance and $X$ is the concentration in $\mu \mathrm{g} \mathrm{mL}^{-1}$.

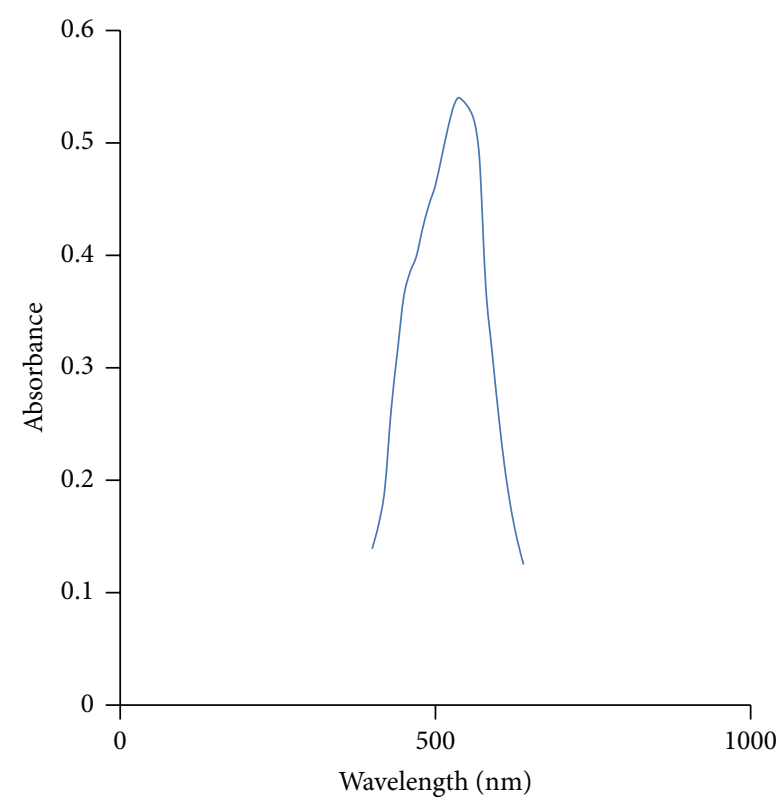

FIGURE 3: Absorption maximum for method B.

was investigated by applying the continuous variation (Job's) and mole ratio methods [22] using equimolar solutions of the reagents. As shown in Figures 6 and 7, the molar ratio which gave maximum absorbance is found to be $1: 1$ (drug: reagent) for SEG-MBTH system and 1:2 for Cu-ligand system. In view of this result, a reaction mechanism is proposed for the developed method.

3.5. Interference Studies. In pharmaceutical analysis, it is important to test the selectivity towards the excipients added to the pharmaceutical preparations. The effects of the excipients associated with formulations of SEG in its pure form and its formulations were investigated using the developed methods. This method does not suffer any interference from commonly associated excipients such as sucrose, lactose, dextrose, starch, and sodium chloride in the preparation of tablets. Data of the interference studies are given in Table 3.

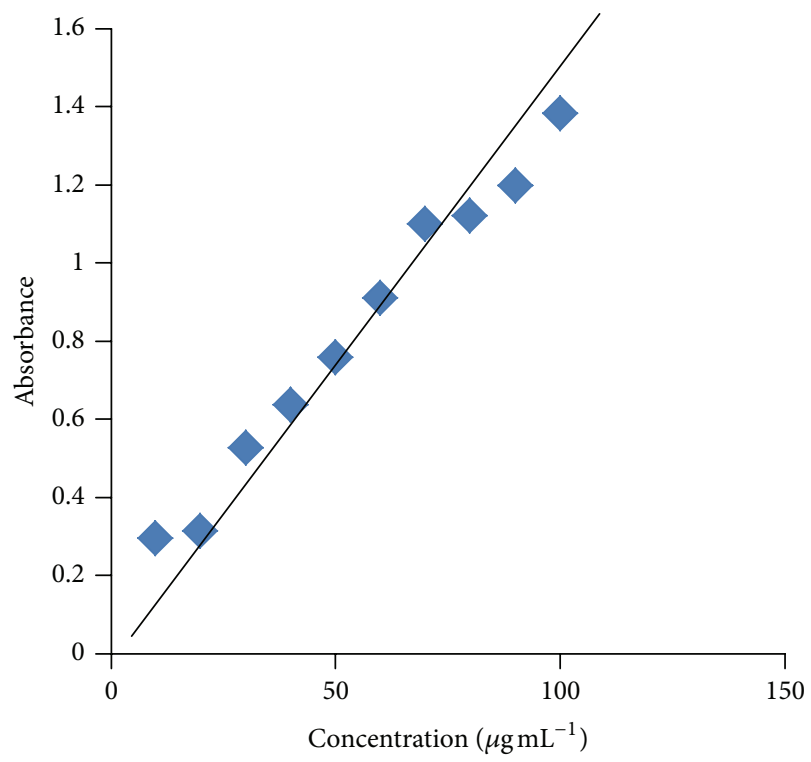

Figure 4: Calibration curve for method A.

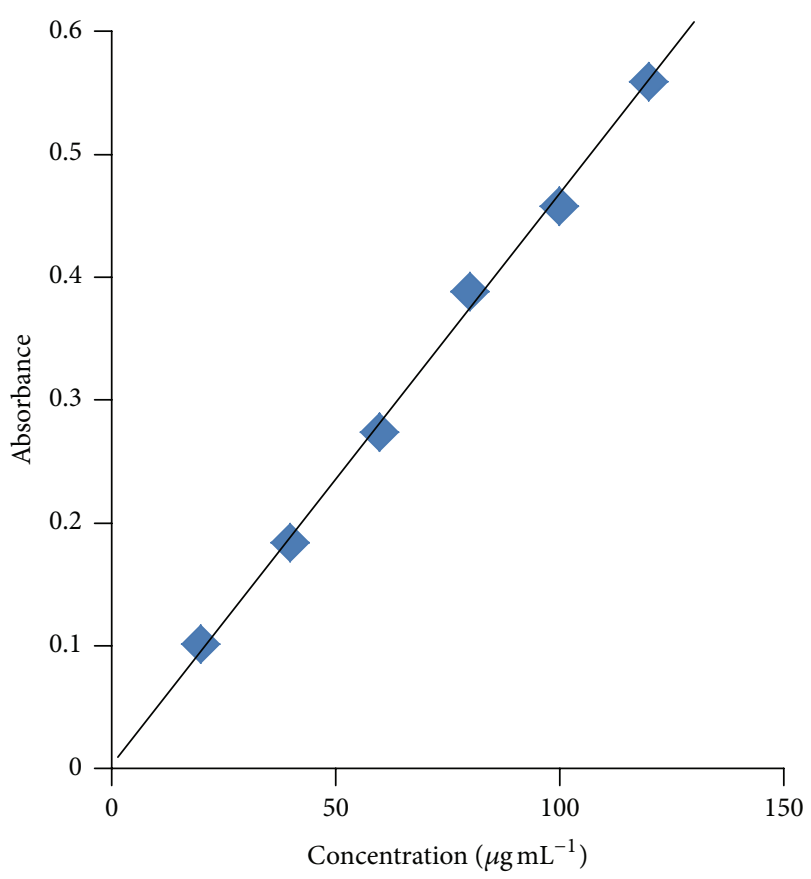

FIGURE 5: Calibration curve for method B.

3.6. Analytical Application. Commercial formulations (tablets) containing $5 \mathrm{mg}$ of SEG were successfully analyzed by the proposed methods. The results obtained for the Student's $t$-test at $95 \%$ confidence level are less than the theoretical values, which confirm the good accuracy of the methods. Obtained values were listed in Table 4. However, there is no method described in the literature for the assay of SEG in pharmaceutical preparations. Thus the present work reports an elegant method for the determination of SEG in pure and pharmaceutical formulations. 
TABLE 2: Evaluation of accuracy and precision.

(a) Method A

\begin{tabular}{lcccc}
\hline Amount taken $\left(\mu \mathrm{g} \mathrm{mL}^{-1}\right)$ & Amount found $^{*}\left(\mu \mathrm{g} \mathrm{mL}^{-1}\right)$ & $\mathrm{RE}(\%)$ & $\mathrm{SD}^{(}\left(\mu \mathrm{gL}^{-1}\right)$ & 0.39 \\
\hline 50.00 & 49.84 & 0.32 & 0.11 & 0.78 \\
60.00 & 59.96 & 0.06 & 0.41 & 0.18 \\
70.00 & 69.83 & 0.24 & 0.58 \\
\hline
\end{tabular}

(b) Method B

\begin{tabular}{lcccc}
\hline Amount taken $\left(\mu \mathrm{g} \mathrm{mL}^{-1}\right)$ & Amount found $\left(\mu \mathrm{g} \mathrm{mL}^{-1}\right)$ & $\mathrm{RE}(\%)$ & $\mathrm{SD}\left(\mu \mathrm{g} \mathrm{mL} L^{-1}\right)$ & 0.22 \\
\hline 20.00 & 20.27 & -1.35 & 0.41 & 1.08 \\
40.00 & 39.82 & 0.45 & 0.81 & 1.02 \\
60.00 & 59.51 & 0.81 & 0.3 \\
\hline
\end{tabular}

${ }^{*}$ Mean value of five determination processes.

RE: relative error; SD: standard deviation; RSD: relative standard deviation.

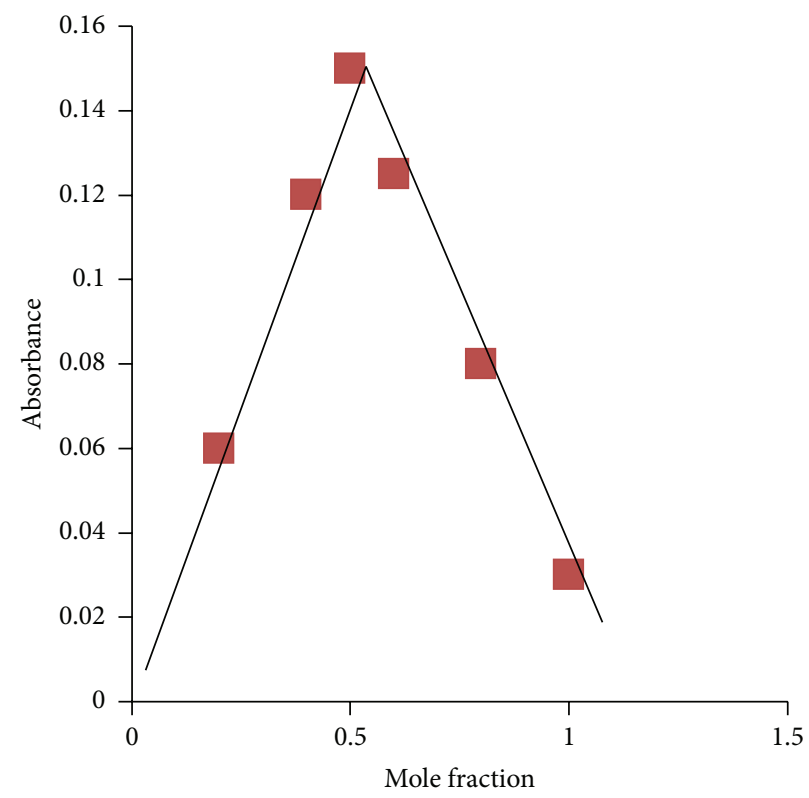

FIgURE 6: Application of Job's method to method A.

TABLE 3: Effect of excipients on assay of SEG.

\begin{tabular}{lccc}
\hline Excipient & $\begin{array}{c}\text { Excipient } \\
\text { taken }(\mathrm{mg})\end{array}$ & $\begin{array}{c}\text { \% recovery* of drug } \pm \text { \% RSD } \\
\text { Method A }\end{array}$ & Method B \\
\hline Glucose & 50 & $99.63 \pm 1.43$ & $99.97 \pm 0.22$ \\
Lactose & 50 & $99.86 \pm 0.10$ & $99.72 \pm 0.52$ \\
Dextrose & 35 & $99.66 \pm 1.27$ & $99.98 \pm 0.27$ \\
Sodium chloride & 25 & $99.90 \pm 0.73$ & $99.90 \pm 0.07$ \\
Starch & 80 & $99.86 \pm 0.43$ & $99.95 \pm 0.26$ \\
\hline
\end{tabular}

${ }^{*}$ Average for five determination processes.

\section{Conclusions}

The developed spectrophotometric methods are quite simple and do not require any pretreatment of the drug and tedious extraction procedure. The $\lambda_{\max }$ in both the methods was
TABLE 4: Result of assay of formulation by the proposed method.

\begin{tabular}{lccc}
\hline \multirow{2}{*}{ Brand name } & \multirow{2}{*}{ SEG certified $(\mathrm{mg})$} & \multicolumn{2}{c}{ Found ${ }^{*} \pm$ SD } \\
& \multirow{2}{*}{5} & Method A & Method B \\
\hline Selegiline & & $t=0.01 \pm 0.16$ & $5.06 \pm 0.35$ \\
& & $t=0.97$ \\
\hline
\end{tabular}

* Mean of five determination processes.

Tabulated $t$ value at $95 \%$ confidence level is 2.77 .

considerably higher which is a decisive advantage and interferences by common excipients are generally very less. The described procedure is reliable, very simple, and conveniently applicable in most laboratories due to the accessibility of the reagents employed and reasonably low time of analysis. Thus, these methods can be used for routine analysis of SEG in pharmaceutical industries, hospitals, and research laboratories. 


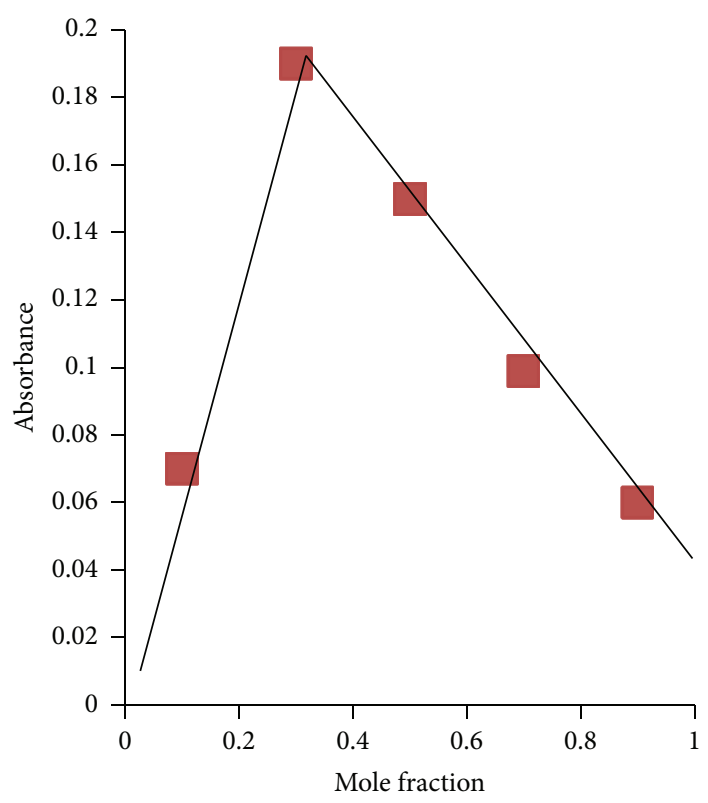

Figure 7: Application of Job's method to method B.

\section{Conflict of Interests}

The authors declare that there is no conflict of interests regarding the publication of this paper.

\section{Acknowledgments}

The authors are thankful to CAD Pharma Inc., Bangalore, India, for providing the drug sample. Badiadka Narayana thanks UGC for financial assistance through BSR one-time grant for the purchase of chemicals. Kumble Divya thanks DST-PURSE project for the financial support.

\section{References}

[1] W. Birkmayer, J. Knoll, P. Riederer, and M. B. Youdim, “(-)Deprenyl leads to prolongation of L-dopa efficacy in Parkinson's disease," Modern problems of pharmacopsychiatry, vol. 19, pp. 170-176, 1983.

[2] A. Clarke, F. Brewer, E. S. Johnson et al., "A new formulation of selegiline: improved bioavailability and selectivity for MAO-B inhibition," Journal of Neural Transmission, vol. 110, no. 11, pp. 1241-1255, 2003.

[3] J. Birks and L. Flicker, "Selegiline for Alzheimer's disease," Cochrane Database of Systematic Reviews, no. 1, Article ID CD00044, 2003.

[4] H. Allain, J. Cougnard, and H.-C. Neukirch, "Selegiline in de novo parkinsonian patients: the French selegiline multicenter trial (FSMT)," Acta Neurologica Scandinavica, Supplement, vol. 84, no. 136, pp. 73-78, 1991.

[5] J. D. Amsterdam, "A double-blind, placebo-controlled trial of the safety and efficacy of selegiline transdermal system without dietary restrictions in patients with major depressive disorder," Journal of Clinical Psychiatry, vol. 64, no. 2, pp. 208-214, 2003.

[6] B. G. Katzung, Basic \& Clinical Pharmacology, Lange Medical Books, McGraw-Hill, New York, NY, USA, 9th edition, 2004.
[7] J. A. Braddock, D. B. Church, I. D. Robertson, and A. D. J. Watson, "Inefficacy of selegiline in treatment of canine pituitary-dependent hyper-adrenocorticism," Australian Veterinary Journal, vol. 82, no. 5, pp. 272-277, 2004.

[8] S. Pichini, R. Pacifici, M. Pellegrini et al., "Development and validation of a high-performance liquid chromatographymass spectrometry assay for determination of amphetamine, methamphetamine, and methylenedioxy derivatives in meconium," Analytical Chemistry, vol. 76, no. 7, pp. 2124-2132, 2004.

[9] K. Nishida, S. Itoh, N. Inoue, K. Kudo, and N. Ikeda, "High-performance liquid chromatographic-mass spectrometric determination of methamphetamine and amphetamine enantiomers, desmethylselegiline and selegiline, in hair samples of long-term methamphetamine abusers or selegiline users," Journal of Analytical Toxicology, vol. 30, no. 4, pp. 232-237, 2006.

[10] M. H. Slawson, J. L. Taccogno, R. L. Foltz, and D. E. Moody, "Quantitative analysis of selegiline and three metabolites (Ndesmethylselegiline, methamphetamine, and amphetamine) in human plasma by high-performance liquid chromatographyatmospheric pressure chemical ionization-tandem mass spectrometry," Journal of Analytical Toxicology, vol. 26, no. 7, pp. 430-437, 2002.

[11] R. La Croix, E. Pianezzola, and M. S. Benedetti, "Sensitive highperformance liquid chromatographic method for the determination of the three main metabolites of selegiline (L-deprenyl) in human plasma," Journal of Chromatography B, vol. 656, no. 1, pp. 251-258, 1994.

[12] M. Katagi, M. Tatsuno, A. Miki, M. Nishikawa, K. Nakajima, and H. Tsuchihashi, "Simultaneous determination of selegiline-N-oxide, a new indicator for selegiline administration, and other metabolites in urine by high-performance liquid chromatography-electrospray ionization mass spectrometry," Journal of Chromatography B, vol. 759, no. 1, pp. 125-133, 2001.

[13] G. Szebeni, J. Lengyel, G. Szekacs, K. Magyar, J. Gaal, and I. Szatmari, "Gas chromatographic procedure for simultaneous determination of selegiline metabolites, amphetamine, 
methamphetamine and demethyl-deprenyl in pig plasma," Acta Physiologica Hungarica, vol. 83, no. 2, pp. 135-141, 1995.

[14] K. S. Patrick, B. Lan Nguyen, and J. D. McCallister, "Gas chromatographic-mass spectrometric determination of plasma selegiline using a deuterated internal standard," Journal of Chromatography, vol. 583, no. 2, pp. 254-258, 1992.

[15] H. H. Maurer and T. Kraemer, "Toxicological detection of selegiline and its metabolites in urine using fluorescence polarization immunoassay (FPIA) and gas chromatography-mass spectrometry (GC-MS) and differentiation by enantioselective GC-MS of the intake of selegiline from abuse of methamphetamine or amphetamine," Archives of Toxicology, vol. 66, no. 9, pp. 675-678, 1992.

[16] J. Netriová, J. Sádecká, and I. Skačáni, "Spectrofluorimetric determination of selegiline," Farmaceuticky Obzor, vol. 74, no. 7, pp. 181-186, 2005.

[17] M. Hasegawa, K. Matsubara, S. Fukushima, C. Maseda, T. Uezono, and K. Kimura, "Stereoselective analyses of selegiline metabolites: possible urinary markers for selegiline therapy," Forensic Science International, vol. 101, no. 2, pp. 95-106, 1999.

[18] R. G. Vijaya, Y. Triveni, K. Divya, N. K. Lakshmi, and G. G. Venu, "Application of MBTH and sulphanilic acid for the quantitative spectrophotometric determination of diacerein in bulk and formulations," Der Pharma Chemica, vol. 1, no. 2, pp. 285-229, 2009.

[19] E. Sawicki, T. W. Stanley, T. R. Hauser, W. Elbert, and J. L. Noe, "Spot test detection and colorimetric determination of aromatic amines and imino heteroaromatic compounds with 3-methyl2-benzothiazolone hydrazone," Analytical Chemistry, vol. 33, no. 6, pp. 722-725, 1961.

[20] N. Theia Al-Sabha, "Spectrophotometric assay of phenylephrine hydrochloride using 4-aminoantipyrine and copper (II)," Pakistan Journal of Analytical and Environmental Chemistry, vol. 11, no. 1, pp. 01-07, 2010.

[21] International Conference on Harmonization (ICH) Guidelines, http://www.ICH.org/.

[22] G. D. Christian and J. E. O’Rilly, "Jobs method," in Instrumental Analysis, Prentice Hall, Upper Saddle River, NJ, USA, 2nd edition, 1980. 

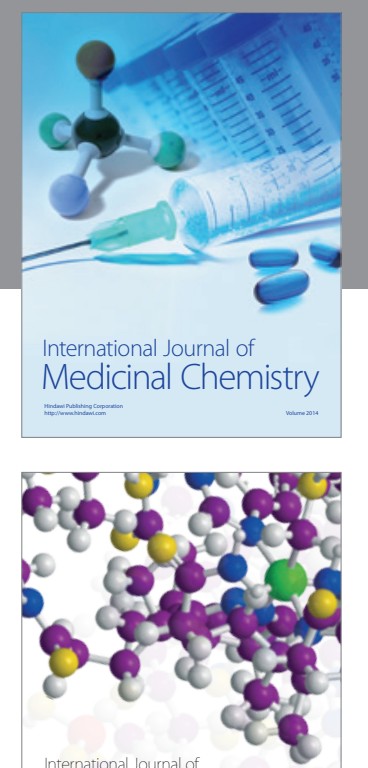

\section{Carbohydrate} Chemistry

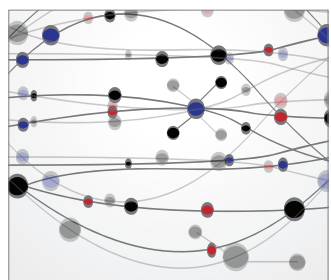

The Scientific World Journal
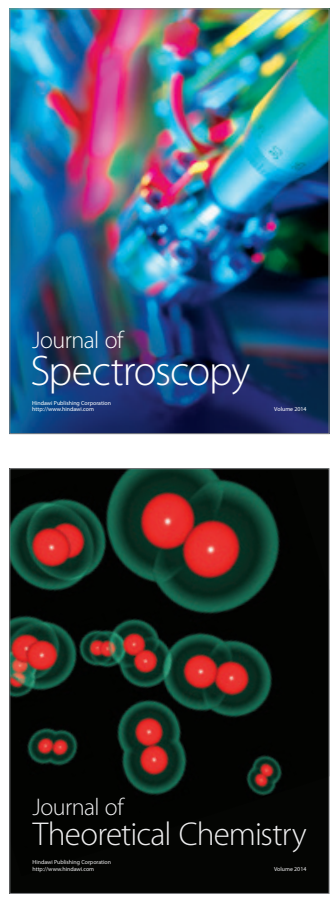
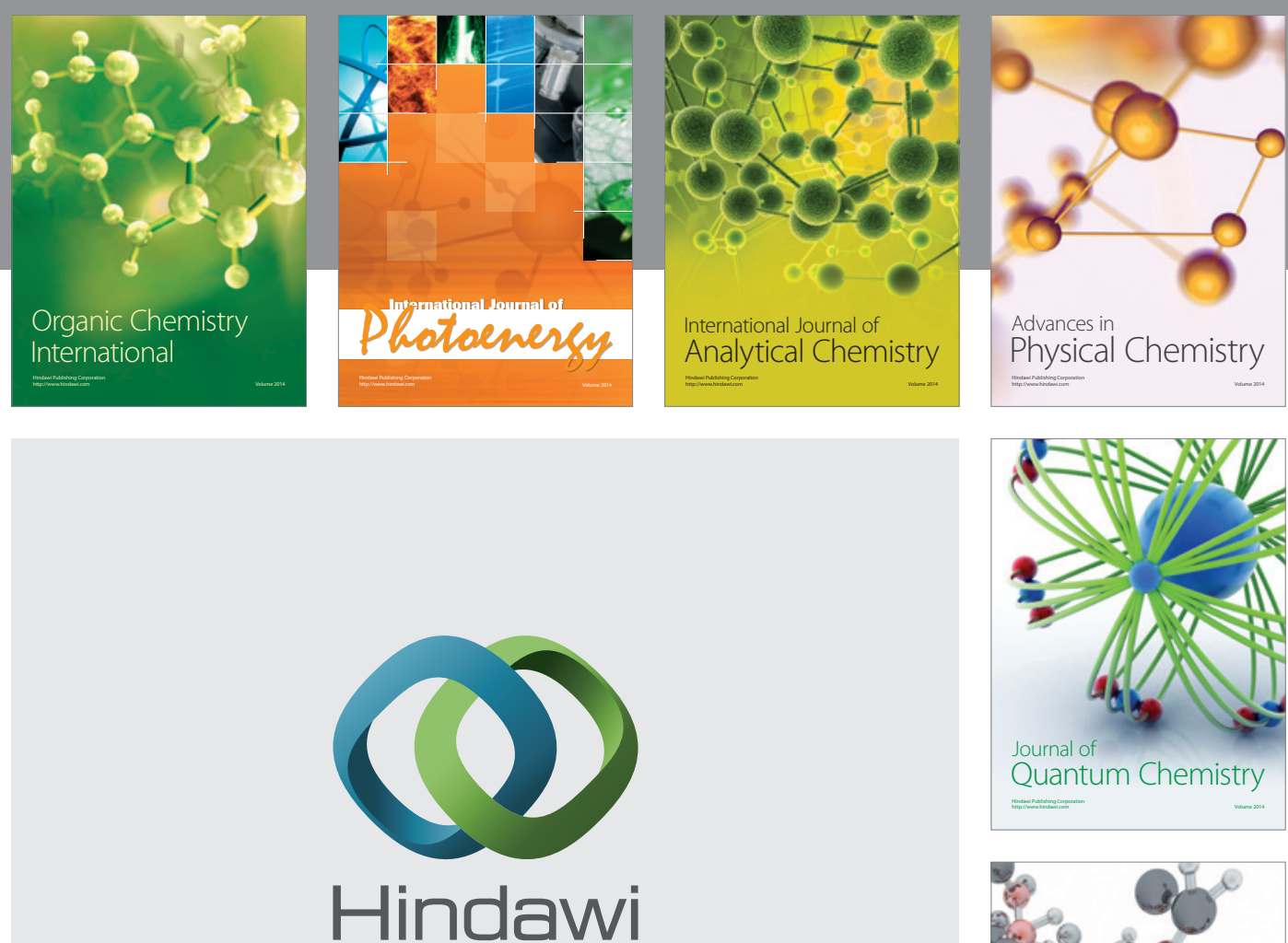

Submit your manuscripts at

http://www.hindawi.com

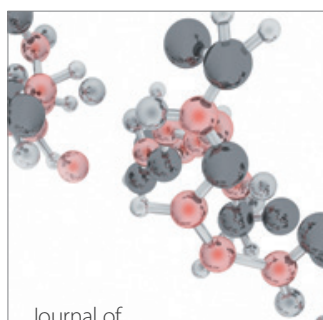

Analytical Methods

in Chemistry

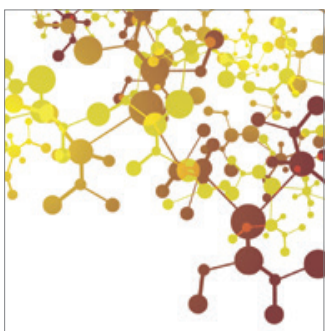

Journal of

Applied Chemistry

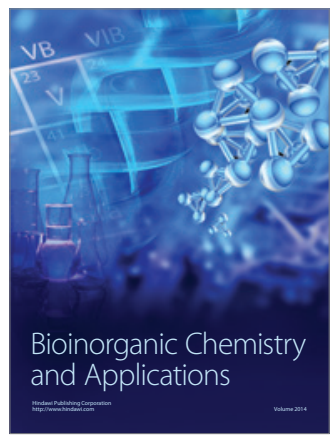

Inorganic Chemistry
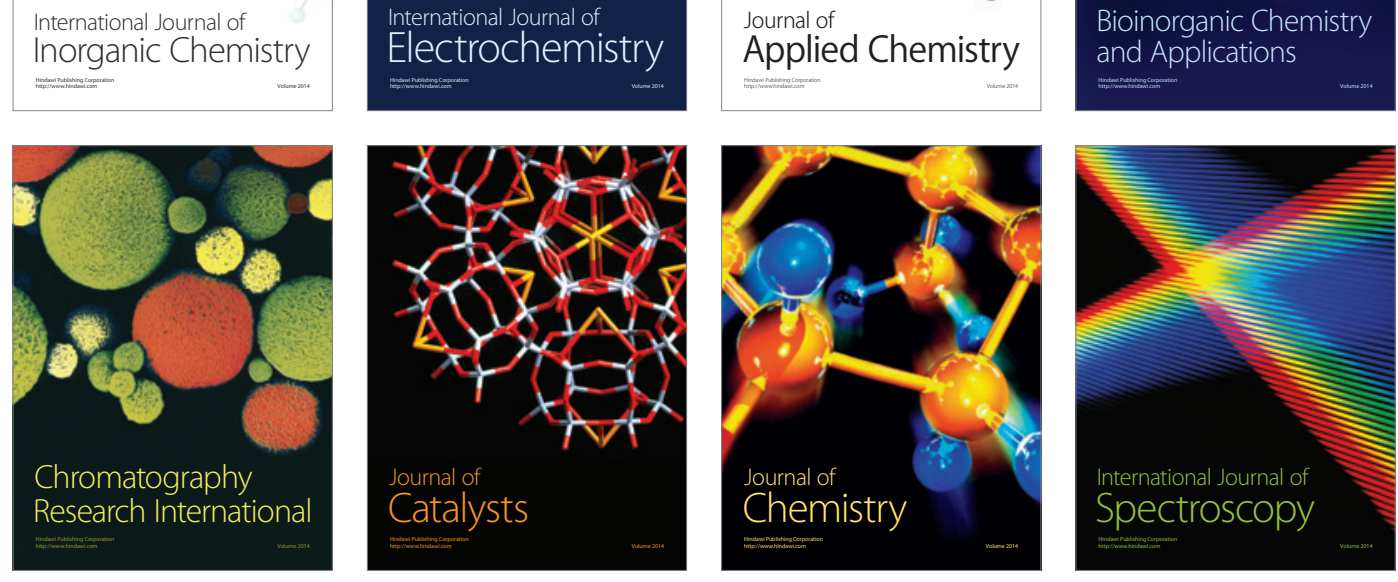